\title{
ANALISIS PENERAPAN FOUR LEVERS OF CONTROL : STUDI KASUS PT JASA MARGA (PERSERO) TBK
}

\author{
Sri Astuty Ratnasari Manggu \\ sriastutyrm@gmail.com \\ (Dosen Fakultas Ekonomi Universitas Sulawesi Barat)
}

\begin{abstract}
This research analyses an implementation of four levers of control in PT Jasa Marga (Persero) Tbk which are belief system, boundary system, diagnostic control system and interactive control system. The research methodology is qualitative descriptive that uses primary and secondary data. In belief system, the company communicates its core values with vision, mission statement, and corporate values. The company reduces risk by regulating employee's behavior in its agreement with union labor, code of conduct and by implementing an investment policy as part of its boundary system. For the interactive control system, the company monitors interactively certain indicators in the balanced scorecard. In the diagnostic control system, the company evaluate an implementation of its strategy by monitoring indicators not only in the balanced scorecard and but also evaluating variances in its management reports.
\end{abstract}

\section{Key words: Management Control System, Levers of Control}

\begin{abstract}
Abstrak
Penelitian ini membahas tentang penerapan four levers of control di Jasa Marga yang meliputi: belief system, boundary system, diagnostic control system dan interactive control system di PT Jasa Marga (Persero) Tbk. Penelitian ini adalah penelitian kualitatif-deskriptif dengan menggunakan data primer dan sekunder. Dalam belief system-nya perusahaan menggunakan pernyataan visi, misi dan tata nilai sebagai cara perusahaan mengkomunikasikan core values-nya. Sementara itu, untuk menghindari risiko, perusahaan menetapkan batasan melalui adanya pedoman perilaku dan peraturan yang tertuang dalam PKB serta batasan strategis dalam hal investasi jalan tol sebagai boundary system-nya. Pada sistem interaktifnya, perusahaan hanya memilih KPI tertentu sebagai variabel/indikator yang akan dimonitor secara interaktif, sementara itu untuk sistem diagnostiknya perusahaan tidak hanya menggunakan balanced scorecard namun juga menggunakan beberapa laporan yang ada di dalam perusahaan.
\end{abstract}

\section{Kata kunci: Sistem Pengendalian, Levers of Control}

\section{PENDAHULUAN}

Dalam kaitannya dengan pengukuran kinerja dan sistem kontrol, Simons (2000) memperkenalkan suatu model yang terintegrasi yang dinamakan Levers of Control. Levers of Control merupakan suatu kerangka yang dicetuskan oleh Simons (2000) yang bertujuan agar para manajer dapat mendiagnosa organisasi atau perusahaan untuk menetapkan kapan dan bagaimana mengaplikasikan levers tersebut pada lingkungan yang berbeda-beda dalam rangka pencapaian tujuan dan strategi organisasi tersebut. 
Belief system merupakan sistem formal yang digunakan oleh top manajer untuk mendefinisikan, mengkomunikasikan dan memperkuat nilai dasar, tujuan dan arahan bagi perusahaan. Dalam praktiknya belief system ini dibuat dalam suatu dokumen formal seperti paham/kepercayaan, misi, serta pernyataan tujuan perusahaan. Boundary system merupakan sistem formal yang digunakan oleh top manajer untuk membuat batasan dan aturan yang harus dipatuhi. Pada praktiknya boundary system ini tercermin melalui business conduct, sistem perencanaan strategi dan prosedur operasional perusahaan. Diagnostic control system merupakan sistem feedback formal yang digunakan untuk memonitor hasil perusahaan dan deviasi yang timbul atas pengukuran kinerja. Interactive control system merupakan sistem formal yang digunakan oleh top manajer untuk secara personal dan reguler mengikutsertakan bawahan dalam kegiatan pengambilan keputusan (Simons, 1995:2). Berikut gambar model Levers of Control:

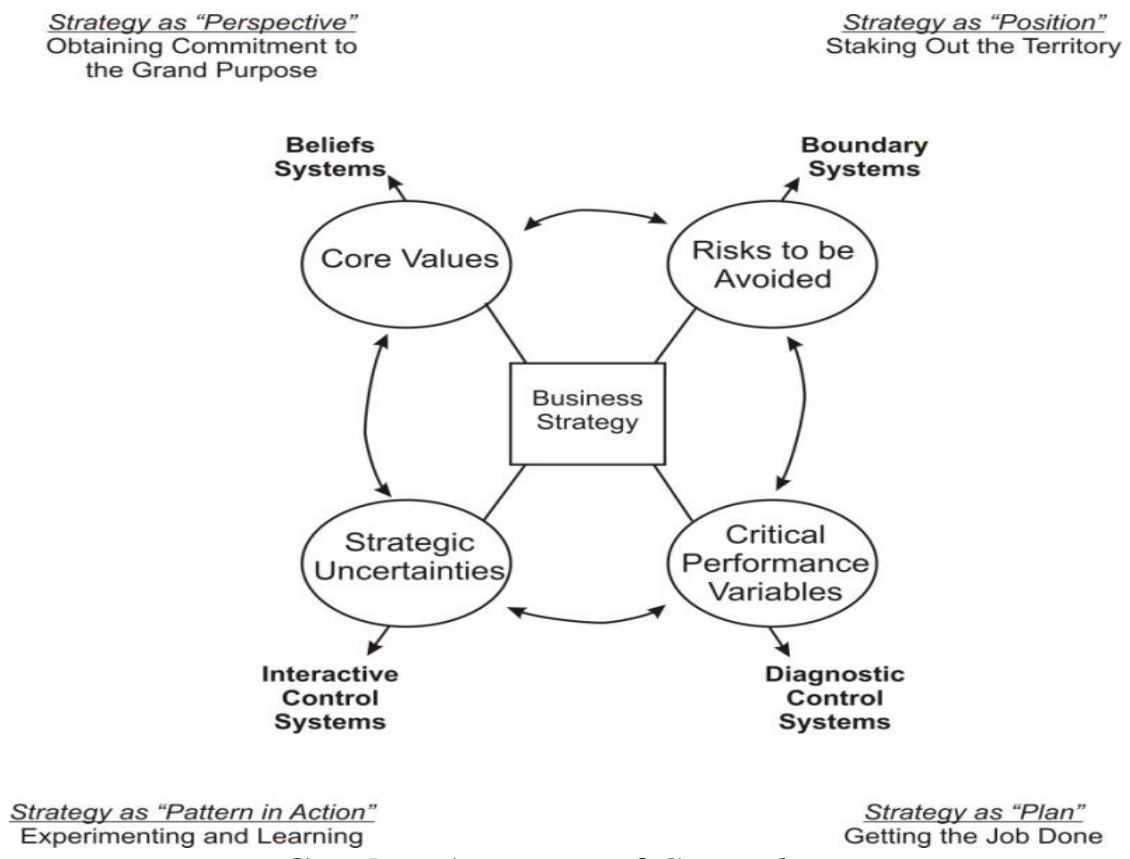

Gambar 1. Levers of Control

Sumber: Simons (2000)

Dua sistem yang pertama yaitu belief system dan interactive control system bersamasama memotivasi individu dalam organisasi untuk secara kreatif melakukan pencarian dan memperluas ruang bagi pencarian peluang. Kedua sistem ini menciptakan motivasi intrinsik dengan cara menyediakan lingkungan informasi yang positif yang mendorong proses pembelajaran dan pertukaran informasi. Oleh karena itu, kedua sistem ini kemudian disebut sebagai sistem positif "the yang of Chinese philosophy." Selanjutnya yaitu dua sistem lainnya, boundary systems dan diagnostic control systems digunakan untuk membatasi perilaku pencarian peluang dan mengalokasikan keterbatasan perhatian individu dalam organisasi. Kedua sistem ini didasarkan pada motivasi ekstrinsik dengan cara menyediakan tujuan secara eksplisit, sistem penghargaan berdasarkan perhitungan tertentu, dan kejelasan batasan untuk pencarian peluang. Oleh karena itu kedua sistem ini disebut sebagai sistem negatif "the yin of Chinese philosophy" (Simons, 2000). 
Sebagai perusahaan jalan tol pertama di Indonesia, dengan pengalaman lebih dari 32 tahun dalam membangun dan mengoperasikan jalan tol, saat ini PT. Jasa Marga (Persero) Tbk adalah pimpinan dalam industrinya dengan mengelola lebih dari $531 \mathrm{~km}$ jalan tol atau $72 \%$ dari total jalan tol di Indonesia. Sebagai perusahaan infrastruktur penyedia jalan tol, keberadaan PT. Jasa Marga (Persero) Tbk sangat dibutuhkan oleh masyarakat luas. Namun sebagai sebuah perusahaan yang cukup besar, PT Jasa Marga (Persero) Tbk tentu tetap ingin mempertahankan posisinya, sehingga strategi bisnis adalah hal yang penting bagi perusahaan untuk dapat mempertahankan posisinya tersebut. Tidak hanya dalam hal perencanaan dan pemilihan strategi bisnis, proses pengimplementasian strategi juga menjadi hal yang perlu diperhatikan oleh PT Jasa Marga (Persero) Tbk dikarenakan kondisi perusahaan yang semakin besar dan semakin kompleks.

Tujuan dari penelitian ini adalah untuk mengetahui bagaimana penerapan konsep four levers of control yang dijelaskan oleh Simon (2000) tersebut pada PT Jasa Marga (Persero) Tbk dan apakah keseluruhan konsep four levers of control yang dijelaskan oleh Simon (2000) tersebut perlu diterapkan pada PT Jasa Marga (Persero) Tbk.

\section{METODE PENELITIAN}

Penelitian ini dilakukan melalui riset kepustakaan yang dilakukan meliputi bahan bacaan, jurnal, artikel manajemen dan akuntansi serta karangan ilmiah yang berkaitan dengan topik serta riset media elektronik yang dilakukan dengan menggunakan fasilitas internet dengan tujuan untuk memperoleh bahan-bahan yang terkait dengan topik penelitian. Selain itu dilakukan pula riset lapangan yang dilakukan dengan cara mengadakan observasi langsung ke perusahaan yaitu PT. Jasa Marga (Persero) Tbk dan melakukan wawancara dengan karyawan yang berkompeten serta memperoleh data-data yang terkait dengan topik yang dibahas dengan tujuan untuk memperoleh gambaran sesuai topik penelitian.

\section{Hasil \& Diskusi}

\section{a. Belief System}

Belief system perusahaan tercermin pada visi, misi serta tata nilai yang dimilikinya. Pernyataan visi, misi dan tata nilai tersebut telah dibuat dalam bentuk formal dan dikomunikasikan melalui berbagai media ke seluruh pihak yang berkaitan dengan perusahaan.

Evaluasi atas belief system perusahaan tersebut menunjukkan bahwa perusahaan telah memiliki suatu sistem formal yang menyatakan tentang arah dan tujuan serta values perusahaan yang dinyatakan melalui visi, misi dan tata nilai yang menggambarkan belief system perusahaan. Pernyataan belief system ini telah dikomunikasikan melalui berbagai media komunikasi yang cukup luas kepada seluruh pihak yang berkaitan dengan perusahaan tidak hanya kepada para karyawannya namun juga sampai kepada para pemegang saham dan juga pemerintah.

Akan tetapi pola komunikasi ini belum diikuti dengan adanya survei untuk mengukur kepedulian dan pemahaman dari para karyawan akan belief system tersebut. Terkait pernyataan misinya, pernyataan misi yang dibuat lebih diarahkan kepada tujuan pencapaian target bisnis semata dan tidak menyebutkan tujuan yang lebih luas terkait manfaat dan alasan keberadaan perusahaan bagi masyarakat, pengguna jalan atau stakeholder lainnya. Selain itu, berdasarkan hasil wawancara diperoleh bahwa sebagian 
besar karyawan tidak memahami dan bahkan tidak dapat menyebutkan visi dan misi perusahaan tersebut.

\section{b. Boundary System}

Boundary system perusahaan meliputi 2 (dua) hal yaitu business conduct boundary dan juga strategic boundary. Evaluasi atas boundary system menunjukkan bahwa perusahaan telah memiliki dan menerapkan business conduct boundaries melalui adanya pedoman perilaku (code of conduct) dan PKB (Perjanjian Kerja Bersama). Code of conduct yang dibuat perusahaan telah memuat aturan-aturan yang jelas dan komprehensif yang dinyatakan secara tegas mengenai hal-hal yang tidak diinginkan atau dilarang oleh perusahaan serta dilengkapi pula dengan penegasan akan sanksi yang akan diberikan apabila terjadi pelanggaran atas pedoman perilaku tersebut. Penerapan code of conduct di perusahaan ini juga tidak hanya sebatas pengungkapan peraturan semata namun perusahaan juga meminta komitmen nyata seluruh karyawannya dengan adanya kewajiban untuk menandatangani pakta integritas sebagai bentuk komitmen pelaksanaan code of conduct tersebut bagi seluruh karyawan termasuk pihak manajemen perusahaan.

Sementara itu, evaluasi atas strategic boundaries PT Jasa Marga (Persero) Tbk menunjukkan bahwa perusahaan telah memiliki batasan strategis yang dinyatakan dan dikomuniksikan secara jelas dalam RJP (Rencana Jangka Panjang) perusahaan. Dalam RJP tersebut, perusahaan menyatakan bahwa hanya melakukan bisnis dalam hal pengembangan dan pengoperasian usaha tol dan non tol. Pengembangan dan pengoperasian usaha tol ini sejalan dengan apa yang menjadi core competencies perusahaan yaitu sebagai pengembang dan pengoperasi mayoritas jalan tol di Indonesia yang telah berpengalaman dalam pengelolaan jalan tol selama lebih dari 31 tahun. Selain itu, perusahaan juga telah menyatakan secara tegas ketentuan investasi jalan tol yang diperbolehkan oleh perusahaan. Hal ini dilakukan perusahaan agar para manajer baik dikantor cabang maupun anak perusahaan, dalam melakukan investasi agar sesuai dengan persyaratan yang ditetapkan perusahaan untuk menghindari risiko-risiko yang tidak diinginkan dan juga melakukan pengelolaan atas risiko-risiko yang teridentifikasi sebagai bagian dari tanggung jawab rencana kerja/program kerja masing-masing unit.

\section{c. Diagnostic Control System}

Evaluasi atas diagnostic control system PT Jasa Marga (Persero) Tbk menunjukkan bahwa perusahaan telah memiliki beberapa alat yang digunakan sebagai diagnostic control system-nya yaitu:

1. RKAP (Rencanan Kerja dan Anggaran Perusahaan). RKAP memuat programprogram kerja yang akan dijalankan selama satu tahun ke depan. RKAP ini dilakukan pemantauan setiap triwulan untuk melihat progres dari program kerja tersebut. Selain itu, dalam RKAP juga terdapat rencana anggaran mencakup pembiayaan dan investasi. Sehingga dengan menggunakan RKAP ini, setiap triwulan dapat dilakukan evaluasi untuk melihat perbandingan antara rencana dan realisasi anggaran dari masing-masing divisi.

2. BSC (Balanced Scorecard). BSC ini digunakan oleh perusahaan sebagai alat (tools) untuk pemantauan pencapaian KPI yang dalam hal ini merupakan critical performance variables yang telah ditetapkan oleh perusahaan yang pemantauannya juga dilakukan setiap triwulan baik untuk BSC korporat, direktorat, cabang, unit kerja kantor pusat maupun anak perusahaan. 
3. Laporan Manajemen. Laporan manajemen ini berisi rangkuman atas pelaporan dari RKAP masing-masing unit dan laporan pencapaian KPI yang oleh pihak manajemen dilaporkan kepada Komisaris.

\section{d. Interactive Control System}

Interactive control system dilakukan oleh perusahaan dengan menggunakan media/alat yang sama dengan yang digunakan pada sistem diagnostiknya yaitu balanced scorecard. Perusahaan memilih beberapa KPI yang mengandung strategic uncertainty yang dirasakan secara strategis dapat berdampak pada kinerja perusahaan dan harus dimonitor secara interaktif, yaitu: kenaikan tarif tol, volume lalu lintas, pembebasan tanah dan progres pembangunan jalan tol. Namun dari keempat KPI yang digunakan perusahaan tersebut, terdapat KPI yang uncontrollable bagi perusahaan yaitu: volume lalu lintas dan kenaikan tarif. KPI yang uncontrollable tidak baik untuk dimonitor secara interaktif, hal ini dikarenakan apabila target yang diinginkan tidak tercapai, maka perusahaan tidak dapat melakukan perbaikan terhadap KPI tersebut. Selain itu, pola interaktif yang terjadi belum cukup baik. Hal ini dikarenakan pola interaktif yang terjadi di perusahaan hanya dilakukan di unit yang terkait terlebih dahulu baru kemudian dilaporkan ke kantor pusat, sehingga tindakan perbaikan yang diambil dapat saja terlambat dan menjadi tidak relevan lagi. Perusahaan juga belum memfasilitasi adanya pola interaktif dengan memediasi karyawan di berbagai tingkatan untuk bersama-sama membahas strategic uncertainty yang terjadi tersebut.

Terkait siklus organisasi, Simons (2000) juga memberikan penekanan tentang kebutuhan setiap sistem pengendalian dalam levers of control di setiap tahapan siklus organisasi tersebut. Hal ini dikarenakan bahwa dalam setiap tahapannya kondisi yang terjadi dalam perusahaan berbeda-beda sehingga membutuhkan kesesuaian sistem pengendalian yang berbeda-beda pula. PT Jasa Marga (Persero) Tbk sebagai perusahaan yang telah beroperasi sejak tahun 1978, saat ini telah menduduki predikat sebagai market leader di industri jalan tol di Indonesia. Kondisi persaingan yang dihadapi tidak terlalu dinamis. Namun, industri jalan tol itu sendiri merupakan industri yang masih sangat berkembang. Total panjang jalan tol yang telah dioperasikan oleh perusahaan dan investor lainya adalah $741,92 \mathrm{~km}$, sedangkan berdasarkan data rekapitulasi perencanaan pembangunan jalan tol (pula Jawa dan luar pulau Jawa) oleh BPJT (Badan Pengatur Jalan Tol), total jalan tol yang masih dibutuhkan adalah sebesar 2.191,9 km (www.bpjt.net). Hal ini menunjukan bahwa masih banyak kesempatan bagi perusahaan untuk terus berkembang dengan kondisi industri bisnis jalan tol yang masih sangat luas, sehingga perusahaan saat ini berada pada tahap growing.

Menyikapi pertumbuhan perusahaan tersebut, perusahaan juga sejak tahun 2009 melakukan perubahan struktur organisasi dari yang semula masih sentralisasi menjadi ke arah desentralisasi dengan menempatkan kantor pusat hanya sebagai investment holding campany serta anak perusahaan dan kantor cabang sebagai SBU (strategic business unit). Proses desentralisasi tersebut kemudian menjadikan perusahaan mendirikan kantor-kantor cabang dan anak perusahaan di berbagai wilayah sesuai dengan wilayah operasional jalan tol yang dikelolanya masing-masing. Hal ini menunjukkan struktur organisasi market based profit centers yang dijalankan oleh perusahaan.

Berdasarkan pemaparan di atas, maka kebutuhan sistem kontrol yang seharusnya diterapkan oleh perusahaan adalah sebagai berikut: 


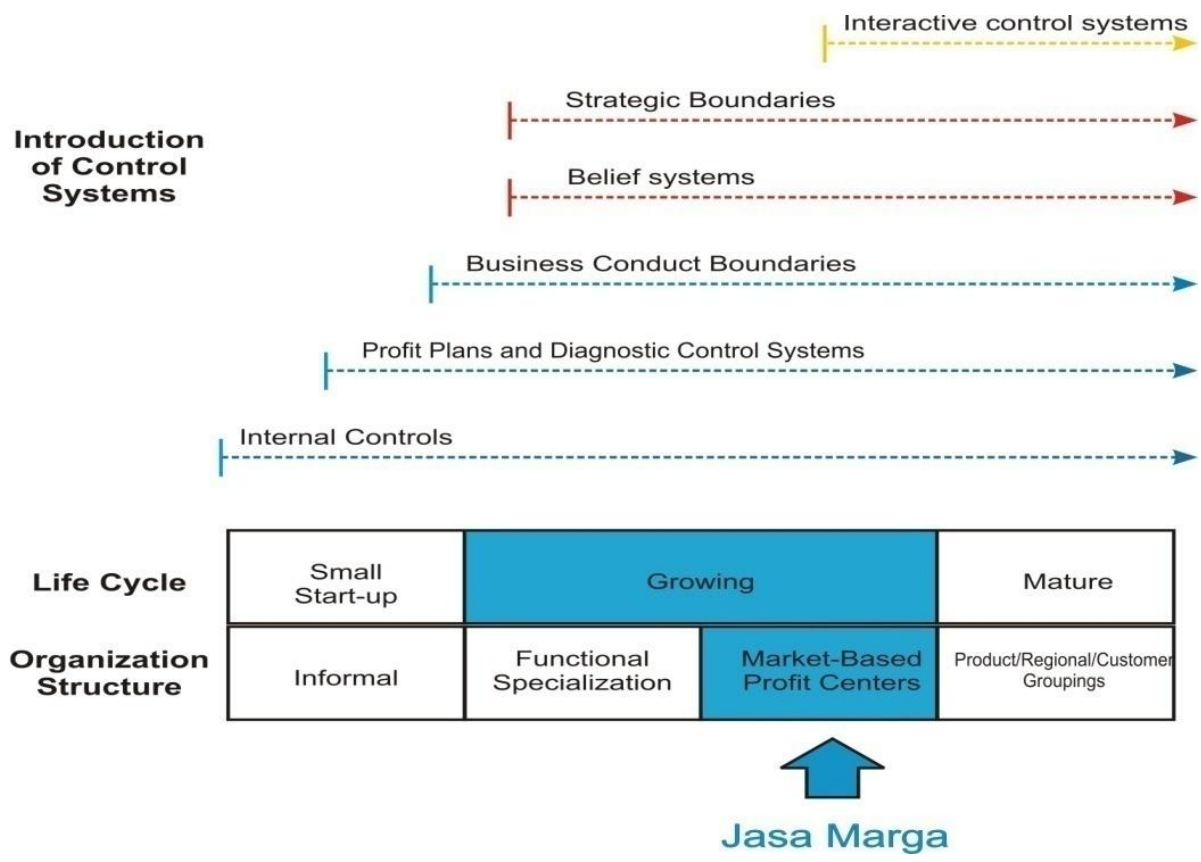

\section{Gambar 2. Penggunaan Sistem Kontrol Selama Siklus Hidup di PT Jasa Marga (Persero) Tbk}

Sumber: Simons (2000), diolah

Berdasarkan gambar di atas, posisi perusahaan yang berada pada tahap growing dengan struktur organisasi yang mencerminkan market based profit centers sebagaimana yang telah dijelaskan sebelumnya, mengharuskan perusahaan memiliki keseluruhan dari sistem pengendalian tersebut yaitu meliputi: internal control, diagnostic control system, business conduct boundary, startegic boundaries, dan interactive control system.

\section{KESIMPULAN}

PT Jasa Marga (Persero) Tbk telah menerapkan sistem pengendalian stratejik berdasarkan konsep four levers of control sebagaimana yang dikemukakan oleh Simon (2000) yaitu meliputi belief system, boundary system, diagnostic control system dan interactive control system. Berikut penerapan levers of control yang telah dilakukan oleh perusahaan beserta alat/media yang digunakan masing-masing:

Keempat kerangka levers of control yaitu belief system, boundary system, diagnostic control system dan interactive control system perlu diterapkan secara keseluruhan pada PT Jasa Marga (Persero) Tbk. Hal ini dikaitkan dengan hubungan antara kebutuhan sistem pengendalian ini dengan siklus organisasi sebagaimana yang dikemukakan oleh Simons (2000). Perusahaan saat ini memiliki struktur organisasi market based profit centers dan berada pada tahap growing. Oleh karena itu keseluruhan dari sistem pengendalian yaitu internal control, belief system, boundary system, diagnostic control system dan interactive control system dibutuhkan oleh perusahaan. 


\section{DAFTAR PUSTAKA}

Porter, Michael, E. (1996). What is Strategy?. Harvard Business Review, NovemberDecember, Number. 96608.

PT Jasa Marga (Persero) Tbk. (09 November 2010). Beranda : Selamat Datang di Jasa Marga. www.jasamarga.com

PT. Jasa Marga (Persero) Tbk. (2010). Laporan Tahunan 2010. Jakarta.

PT. Jasa Marga (Persero) Tbk. (2009). Perjanjian Kerja Bersama Tahun 2009-2011. Jakarta.

Simons, Robert. (1995). How New Top Managers Use Control Systems As Levers of Strategic Renewal. Strategic Management Journal, Vol. 15, 169-189.

Simons, Robert. (2000). Performance Measurement \& Control Systems for Implementing Strategy. New Jersey : Prentice Hall. 